OPEN ACCESS

Edited by:

Paola Aceto,

Catholic University of the Sacred

Heart, Italy

Reviewed by: Mariangela Gulisano,

University of Catania, Italy Jeremy Samuel Stern, St George's, University of London, United Kingdom

*Correspondence:

Francesco Cardona francesco.cardona@uniroma1.it

tThese authors have contributed equally to this work

Specialty section: This article was submitted to Mood and Anxiety Disorders, a section of the journal Frontiers in Psychiatry

Received: 15 July 2020 Accepted: 30 October 2020 Published: 30 November 2020

Citation:

Conte G, Baglioni V, Valente F, Chiarotti F and Cardona F (2020) Adverse Mental Health Impact of the COVID-19 Lockdown in Individuals With Tourette Syndrome in Italy: An

Online Survey.

Front. Psychiatry 11:583744. doi: 10.3389/fpsyt.2020.583744

\section{Adverse Mental Health Impact of the COVID-19 Lockdown in Individuals With Tourette Syndrome in Italy: An Online Survey}

\author{
Giulia Conte ${ }^{1+}$, Valentina Baglioni ${ }^{1+}$, Francesca Valente ${ }^{1}$, Flavia Chiarotti ${ }^{2}$ and \\ Francesco Cardona ${ }^{1 *}$ on behalf of the Tourette Roma onlus \\ 1 Department of Human Neurosciences, Institute of Child and Adolescent Neuropsychiatry, Sapienza University of Rome, \\ Rome, Italy, ${ }^{2}$ Center for Behavioral Sciences and Mental Health, Istituto Superiore di Sanità, Rome, Italy
}

During the early stages of the coronavirus disease 2019 (COVID-19) pandemic in Italy, an online survey was launched via a local patient advocacy website to investigate mental health issues in children and adolescents with Tourette syndrome (TS). Respondents were parents, who were asked to report on their child's general health, tics, comorbidities/problems, pharmacological treatment/psychotherapy, symptom variations, and daily routine, as well as on their family's health and work experiences during the pandemic. Two hundred thirty-eight people participated in the survey, 203 females and 35 males. Our findings indicate that, in the time window of 4-6 weeks after the beginning of the COVID-19-related lockdown, $67 \%$ of individuals with TS developed a relevant worsening of the overall clinical condition as rated by their parents. An improvement or no variation of the clinical picture was reported in 20.5 and $6.7 \%$ of cases, respectively. Most worsened symptoms included tics, hyperactivity, rage attacks, obsessions/compulsions, and anxiety. Of the subjects experiencing a clinical worsening, the majority $(51.76 \%)$ showed variations across two to five symptom domains. No association was found between symptom variation and family demographics or health and economic issues specifically related to the lockdown. The current COVID-19 pandemic is exerting a considerable impact on the mental health of young individuals with TS by worsening both tics and emotional and behavioral symptoms.

Keywords: Tourette syndrome, COVID-19, pandemic, mental health, tics, children, adolescents

\section{INTRODUCTION}

At the end of February 2020, the epicenter of the current coronavirus disease 2019 (COVID-19) pandemic shifted from China to Europe, with Italy being the first country to witness a massive peak in infections and fatalities $(1,2)$. In the past few months, the Italian government has put forward unprecedented measures to contain the outbreak, placing residents in a nationwide lockdown, and banning any movement inside the country. Such measures were ongoing until 4 May (3).

Each pandemic poses particular mental health risks in that it implies not only the spreading of a physical illness but also an overflow of anxiety and mass panic as possible reactions to health concerns. Moreover, common measures implemented by governments to restrain the outbreak, such as social distancing, isolation, and contact tracing policies, may further disrupt the collective 
sense of reality and order, worsening the emotional and psychological burden experienced by individuals (4). Previous research dealing with the mental health impact of pandemics has mainly focused on subjects put into isolation or quarantine, demonstrating psychiatric complications, such as anxiety and depression, in up to $40 \%$ of cases $(5,6)$. In the few studies regarding pediatric populations in similar conditions, externalizing and disruptive behaviors have also been frequently reported $(7,8)$.

Under such circumstances, those with a pre-existing mental health condition and especially children and adolescents with neuropsychiatric disorders appear as a particularly vulnerable population (9).

Tourette syndrome (TS) is a neurodevelopmental chronic condition defined by multiple motor and phonic tics (10). TS is a multifaceted disorder and is highly comorbid with conditions such as obsessive-compulsive disorder (OCD) and anxiety and attention deficit/hyperactivity disorder (ADHD) (11).

Although the underlying pathophysiological mechanisms is still unknown, a distinctive feature of TS is the great temporal variability of symptoms, both of tics and comorbidities (12). In TS patients, symptom expression is also systematically influenced by contextual factors (13) and is generally increased at home than in more social situations (14). Therefore, environmental factors such as the lockdown due to COVID-19 may significantly contribute in TS to concurrent symptom fluctuations, especially through mechanisms of setting modification and habit disruption, as resulting from mass school closures and stay-at-home orders.

In this study, we sought to provide an overview of the emotional and behavioral symptoms expressed by children and adolescents with TS in the early stages of the COVID-19 lockdown in Italy. We were also interested in determining whether symptom variations were associated with any specific sociodemographic variable or with health and economic issues developed during the pandemic within their families.

\section{MATERIALS AND METHODS}

\section{Data Source}

For data collection, a brief online survey was developed by the Department of Human Neurosciences at Sapienza University of Rome and promoted by "Tourette Roma onlus," a local patient advocacy association. The survey was launched on the association's website on 1 April 2020 (i.e., 3 weeks after the beginning of the general lockdown in Italy) and online records were collected until 14 April 2020). The study was conformed to the Declaration of Helsinki, and each submitted record was completely anonymous, therefore exempting the study from institutional Ethics Committee examination. The survey was directed to parents of individuals with TS and included different sections, with a total of 26 multiple-choice questions. Originally, the online form was developed for the parents of children and adolescents; however, a certain number of parents of adult patients also participated. Therefore, we decided to include the latter data in our analysis to offer a wider point of view on the investigated topic.
Participants were asked to report on their child's general health, tics, comorbidities/problems, variations of symptoms during the lockdown, presence and eventual changes in the pharmacological treatment/psychotherapy. Moreover, a survey section was dedicated to family demographics and impact of the pandemic on the child's daily activities as well as on family health and work experiences.

\section{Data Analysis}

Data are presented as absolute and percent frequencies. Percent frequencies were calculated on the number of respondents to each item. The chi-square test was used to assess the effect of both participants' and offspring's variables on the variation of TS symptoms and quality of parent-child relationship. Participants' variables were as follows: age, gender, education, occupation, presence of domestic help before the pandemic (i.e., babysitter, grandparents/relatives looking after the child), geographical area of residence, living with partner, number of offspring and of family members, medical problems related to COVID-19, and economic changes related to the pandemic. Offspring's variables included the following: age, gender, comorbidities, pharmacological therapy and need of eventual adjustment during the lockdown phase, psychotherapy and its eventual variation due to lockdown, and time spent in school and other activities during the lockdown.

Because of the exploratory design of the study, we present the values of significance without correcting for multiple testing.

\section{RESULTS}

\section{Participants}

Two hundred thirty-eight people participated in the survey. Of them, 203 (85.29\%) were females and 35 (14.71\%) males. The general rate of responses was $81 \%$.

Table 1 displays geographic distribution, age, education level, employment status and family demographics of the participants. Participants living in Regions with medium rates of COVID-19 infections (i.e., number of confirmed cases/resident population, following the official data of the Italian Minister of Health updated as of 14 April 2020) were the most prevalent (46.64\%), although highly impacted Regions were also largely represented (39.92\%).

\section{Impact of the COVID-19 Epidemic on Family Health and Parents' Employment and Economic Status}

About a quarter of the participants $(n=60$ out of 230 who answered this question; 26.09\%) have reported COVIDrelated health issues, such as hospitalization, illness or death among family members/friends, quarantine after contact with a confirmed case, or need for swabbing. Remarkably, about $32 \%$ of participants or their partners experienced a considerable reduction of the income due to unexpected lay-off or job uncertainties as a result of the pandemic, with $17 \%$ facing such consequence both themselves and their partners. 
TABLE 1 | Socio-demographic characteristics of participants.

\begin{tabular}{|c|c|c|}
\hline & $n$ & $\%$ \\
\hline \multicolumn{3}{|l|}{ Geographic distribution } \\
\hline $\begin{array}{l}\text { Regions with high number of } \\
\text { confirmed cases* (Lombardy, Veneto, } \\
\text { Emilia-Romagna, Piedmont, } \\
\text { Trentino, Liguria, and Marche) }\end{array}$ & 95 & 39.92 \\
\hline $\begin{array}{l}\text { Regions with medium number of } \\
\text { confirmed cases* (Lazio, Tuscany, } \\
\text { Campania, Abruzzo, Apulia, Friuli VG, } \\
\text { Valle d'Aosta, Molise, and Umbria) }\end{array}$ & 111 & 46.64 \\
\hline $\begin{array}{l}\text { Regions with low number of } \\
\text { confirmed cases* (Calabria, Sicily, } \\
\text { Sardinia, and Basilicata) }\end{array}$ & 32 & 13.44 \\
\hline \multicolumn{3}{|l|}{ Age } \\
\hline 20-30 years & 5 & 2.10 \\
\hline $31-40$ years & 49 & 20.59 \\
\hline $41-50$ years & 120 & 50.42 \\
\hline $51-60$ years & 53 & 22.27 \\
\hline$>61$ years & 11 & 4.62 \\
\hline \multicolumn{3}{|l|}{ Education level } \\
\hline Primary & 5 & 2.10 \\
\hline Lower secondary & 36 & 15.13 \\
\hline Upper secondary & 120 & 50.42 \\
\hline Bachelor or equivalent level & 77 & 32.35 \\
\hline \multicolumn{3}{|l|}{ Employment status } \\
\hline Not employed & 17 & 7.14 \\
\hline Employee & 124 & 52.10 \\
\hline Self-employed or freelancer & 36 & 15.13 \\
\hline Homemaker & 51 & 21.43 \\
\hline Retired & 10 & 4.20 \\
\hline \multicolumn{3}{|l|}{ Number of offspring } \\
\hline 1 & 54 & 23.11 \\
\hline 2 & 144 & 60.50 \\
\hline 3 & 36 & 15.13 \\
\hline$>3$ & 3 & 1.26 \\
\hline \multicolumn{3}{|c|}{ Number of people living at home (including relatives) } \\
\hline 2 & 11 & 4.62 \\
\hline 3 & 62 & 26.05 \\
\hline 4 & 133 & 55.88 \\
\hline 5 & 28 & 11.76 \\
\hline$>5$ & 4 & 1.68 \\
\hline
\end{tabular}

"Number of cases/resident population following the official data of the Italian Minister of Health.

\section{Participants' Offspring With Tourette Syndrome}

We gathered data on 223 participant's offspring with Tourette Syndrome.

Number of males was 188 (84.30\%) and females 35 (15.70\%), male-to-female ratio of 5.4-1.

Eighty-four subjects (37.67\%) were in the age range between 6 and 11 years, $106(47.53 \%)$ between 12 and 18 years, and 33 (14.80\%) were older than 18 years.

Disease duration was of $1-2$ years in 15 cases $(6.73 \%)$, of 3-5 years in $78(34.98 \%)$, of $6-10$ years in $92(41.25 \%)$, and $>10$ years
TABLE 2 | Reported comorbidities in the participants' offspring and symptoms rated as currently most impairing.

\begin{tabular}{|c|c|c|c|c|}
\hline & \multicolumn{2}{|c|}{ Present } & \multicolumn{2}{|c|}{ Currently most impairing } \\
\hline & $n$ & $\%$ & $n$ & $\%$ \\
\hline \multicolumn{5}{|l|}{ Comorbid symptoms } \\
\hline Motor tics & $\mathrm{N} / \mathrm{A}$ & N/A & 45 & 22.84 \\
\hline Phonic tics & $\mathrm{N} / \mathrm{A}$ & N/A & 28 & 14.21 \\
\hline Obsessions/compulsions & 106 & 56.08 & 23 & 11.68 \\
\hline Hyperactivity/inattention & 103 & 54.50 & 19 & 9.64 \\
\hline Rage attacks & 93 & 49.21 & 33 & 16.75 \\
\hline Anxiety & 96 & 50.79 & 10 & 5.08 \\
\hline Depression & 31 & 16.40 & 4 & 2.03 \\
\hline Panic & 17 & 8.99 & 0 & 0 \\
\hline Learning problems & 52 & 27.51 & 0 & 0 \\
\hline Sleep problems & 53 & 28.04 & 5 & 2.54 \\
\hline Food problems & 42 & 22.22 & 4 & 2.03 \\
\hline Other problems & 24 & 12.70 & 12 & 6.09 \\
\hline None & 35 & 15.69 & 14 & 7.11 \\
\hline
\end{tabular}

in 38 (17.04\%). TS diagnosis had been established for 1-2 years in 82 cases $(36.77 \%), 3-5$ years in $82(36.77 \%), 6-10$ years in 40 (17.94\%), and more than 10 years in $19(8.52 \%)$.

One hundred thirty-six (60.99\%) subjects were medicated-of whom, $119(53.36 \%)$ receiving medication for tics and $17(7.62 \%)$ for other neuropsychiatric symptoms-while the remaining 87 (39.01\%) were unmedicated at the time of the investigation.

One hundred thirteen (50.68\%) subjects were receiving psychotherapy (any kind) — of whom, 66 (29.60\%) for tics and 47 $(21.08 \%)$ for other neuropsychiatric symptoms.

Table 2 shows the main reported comorbidities and which symptoms were rated as most impairing by parents during the lockdown period. Major pre-existing comorbidities of our sample were OCD, ADHD, anxiety, and rage attacks, with each disorder affecting about $50 \%$ of individuals. To possibly capture any other problem or symptom not otherwise specified by the survey checklist, an item "other problems" was included (Table 2), which needed a written specification. Symptoms recorded under such label included the following: oppositional behavior $(n=2)$, autism $(n=1)$, bipolar disorder $(n=1)$, non-suicidal self-injurious behaviors $(n=1)$, stuttering $(n=$ $1)$, and bruxism $(n=1)$. Symptoms rated by parents as most impairing during the lockdown included mainly motor and phonic tics (22.84 and $14.21 \%$, respectively), followed by rage attacks (16.75\%), obsessions and compulsions (11.68\%), and hyperactivity/inattention symptoms (9.64\%).

\section{Changes in School and Daily Activities of Offspring During the Lockdown}

One hundred eighty-nine subjects $(87.10 \%)$ were students and participated in online learning at home. Along with online classes, 154 of them (70.97\%) were also doing individual homework. Daily, the time spent in school activities was " $<1 \mathrm{~h}$ " in 43 cases (19.82\%), " $1 \mathrm{~h}$ ” in 33 (15.21\%), “ $2 \mathrm{~h}$ ” in 48 (22.12\%), " $3 \mathrm{~h}$ " in 40 (18.43\%), and "more than $3 \mathrm{~h}$ " in 53 (24.42\%). 
TABLE 3 | Number and percentage of offspring with reported variation of symptoms during the lockdown.

\begin{tabular}{|c|c|c|c|c|}
\hline & $6-11$ years & $12-18$ years & $>18$ years & Total \\
\hline & $n$ & $n$ & $n$ & $n(\%)$ \\
\hline $\begin{array}{l}\text { No variation in any } \\
\text { symptom }\end{array}$ & 8 & 4 & 1 & 13 (6.67\%) \\
\hline $\begin{array}{l}\text { Only improved } \\
\text { symptoms (at least } \\
\text { 1) }\end{array}$ & 11 & 16 & 1 & $28(14.36 \%)$ \\
\hline $\begin{array}{l}\text { Improved symptoms } \\
\text { outnumber the } \\
\text { worsened ones }\end{array}$ & 5 & 4 & 3 & 12 (6.15\%) \\
\hline $\begin{array}{l}\text { Improved symptoms } \\
\text { equal the worsened } \\
\text { ones }\end{array}$ & 1 & 10 & 0 & 11 (5.64\%) \\
\hline $\begin{array}{l}\text { Worsened } \\
\text { symptoms } \\
\text { outnumber the } \\
\text { improved ones }\end{array}$ & 18 & 13 & 4 & 35 (17.95\%) \\
\hline $\begin{array}{l}\text { Only worsened } \\
\text { symptoms (at least } \\
\text { 1) }\end{array}$ & 35 & 45 & 16 & 96 (49.23\%) \\
\hline
\end{tabular}

Apart from school activities, parents reported of their children spending time in the following: video games (n. 150; $69.12 \%)$, social media and chat $(117 ; 53.92 \%)$, table or role games $(64 ; 29.49 \%)$, playing an instrument or singing (38; $17.51 \%)$, household chores $(60 ; 27.65 \%)$, painting $(52 ; 23.96 \%)$, reading novels or comics $(37 ; 17.05 \%)$, and other activities $(63 ; 29.03 \%)$.

\section{Variations in Clinical Symptomatology and in Parent-Child Relationship During the Lockdown}

The participants were asked to report variations of clinical symptoms in their offspring during the lockdown. The variations were expressed through a 5-point Likert scale ("much improved", "improved", "as usual”, "worsened" and "much worsened”).

A significant worsening of the overall clinical picture occurred in two-thirds of the subjects (67.18\%), while 20.51 and $5.64 \%$ experienced, respectively, an improvement or a variation with no clear trend toward improvement/worsening and only $6.67 \%$ reported no variation at all (Table 3). Most worsened symptoms (Table 4), as rated by parents in over $25 \%$ of subjects, included tics, hyperactivity, rage attacks, obsessions/compulsions, and anxiety. Nineteen participants (9.55\% of respondents) also reported of other problems, such as apathy, need for physical contact, stuttering, and argumentative/defiant behavior. Of the subjects experiencing a clinical worsening, the majority $(51.76 \%)$ showed variations across two to five symptom domains (Table 4).

Finally, 111 respondents $(55,78 \%)$ rated the quality of their parent-child relationship during the lockdown as being "as usual," while it "improved" for 51 (25.63\%), and "worsened" for 37 (18.59\%).
TABLE 4 | Type and number of "worsened" or "much worsened" symptoms during the lockdown according to age group.

\begin{tabular}{|c|c|c|c|c|}
\hline & $6-11$ years & $12-18$ years & $>18$ years & Total \\
\hline & $n$ & $n$ & $n$ & $n(\%)$ \\
\hline \multicolumn{5}{|c|}{ Type of symptom "worsened" or "much worsened" } \\
\hline Obsessions/Compulsions & 20 & 25 & 11 & $56(28.28 \%)$ \\
\hline Hyperactivity & 33 & 28 & 7 & $68(34.34 \%)$ \\
\hline Rage attacks & 31 & 23 & 11 & $65(32.82 \%)$ \\
\hline Motor tics & 33 & 41 & 10 & $84(42.42 \%)$ \\
\hline Phonic tics & 29 & 36 & 7 & $72(36.36 \%)$ \\
\hline Anxiety & 19 & 21 & 12 & $52(26.26 \%)$ \\
\hline Depression & 8 & 12 & 8 & $28(14.14 \%)$ \\
\hline Sleep problems & 16 & 23 & 8 & $47(23.74 \%)$ \\
\hline Panic & 7 & 5 & 4 & $16(8.08 \%)$ \\
\hline Eating problems & 11 & 20 & 7 & $38(19.19 \%)$ \\
\hline \multicolumn{5}{|c|}{ Number of symptoms "worsened" or "much worsened" } \\
\hline 0 & 19 & 20 & 2 & $41(20.81 \%)$ \\
\hline 1 & 9 & 16 & 5 & 30 (15.23\%) \\
\hline 2 & 15 & 13 & 3 & $31(15.75 \%)$ \\
\hline 3 & 10 & 13 & 5 & $28(14.21 \%)$ \\
\hline 4 & 12 & 15 & 3 & $30(15.23 \%)$ \\
\hline 5 & 5 & 6 & 2 & 13 (6.59\%) \\
\hline 6 & 7 & 4 & 3 & $14(7.11 \%)$ \\
\hline 7 & 1 & 2 & 0 & 3 (1.52\%) \\
\hline 8 & 2 & 2 & 0 & 4 (2.03\%) \\
\hline 9 & 0 & 1 & 1 & $2(1.01 \%)$ \\
\hline 10 & 0 & 0 & 1 & $1(0.51 \%)$ \\
\hline
\end{tabular}

\section{Associations}

Contingency tables showed only few definite associations between the categorical variables listed in Methods and the variation either of symptoms of TS or of the quality of parentchild relationships during the lockdown.

In particular, a younger participant's age was associated to a worsening in the relationship with their child (33.33 vs. 17.82 vs. $7.69 \%$ in participants aged $\leq 40$ years, $41-50$ years, and $>50$ years, respectively; $p=0.0141$ ). In addition, the quality of the parent-child relationship was associated to the presence of domestic helps before the pandemic, in that "improvement" and "worsening" of the relationship were respectively higher in the group of participants without and with domestic helps (improvement, 42.25\%; worsening, 25.35\%; $p<0.001$ ). Finally, a shorter time dedicated to school activities during the lockdown was associated to a worsening of rage attacks, obsession, and compulsions and of the overall clinical symptomatology ( $p=$ $0.0305, p=0.0309$, and $p=0.0415$, respectively).

\section{DISCUSSION}

Based on parent reports among a national sample, the present study highlights the adverse impact of the COVID-19 pandemic on mental health of individuals with TS.

Although limited by its cross-sectional design, our study points out an important worsening of the overall clinical condition in the time window of 4-6 weeks after the beginning 
of the lockdown. Specifically, over $67 \%$ of parents reported worsening of TS symptoms, while only 20.5 and $6.7 \%$, respectively observed improvement or no variation of the clinical picture. Such large and definite trend toward worsening in our sample seems unlikely related to the polyphasic course of TS, with the typical fluctuations in the severity of tics and associated symptoms. Furthermore, our data do not support any association between variation of symptoms and family health and economic issues related to the pandemic. The latter aspect might reflect either a lack of statistical power of our data or the involvement of other factors contributing to adverse mental health outcomes in our cohort, such as the condition created by the lockdown itself and the inherent daily life disruption.

Tics, especially motor ones, were rated in up to $42 \%$ of cases as the most worsened symptoms. As a general rule, individuals with TS tend to tic less when they are engaged in social situations (e.g., school or work settings) and more when they are relaxed or with family $(14,15)$. In line with this evidence, our data suggest that the prolonged stay-at-home condition during the lockdown may have contributed to tic exacerbation.

Importantly, the specific population here examined was part of a larger community experiencing a collective stressful life event such as the COVID-19 pandemic. Psychosocial stress and adverse life events have been largely implicated not only in tic frequency and severity (16) but also in the worsening of comorbid depression and anxiety in TS (17). Accordingly, we observed an increase of anxiety and obsessive-compulsive symptoms (OCS) in 26 and $28 \%$ of our sample. However, our findings indicate that anxious-depressive symptoms were outreached by externalizing and behavioral problems. Indeed, outbursts of anger ("rage attacks") and problems related to hyperactivity/impulsivity, regarded almost $32-34 \%$ of the subjects and especially those in the younger age groups (6-11 and 12-18 years old). Such different rates of externalizing and internalizing problems parallel the findings from previous studies on hospitalized patients put into isolation [for a review (18)], showing that, while adults were more at risk for depression and general anxiety disorder, children presented more often with externalizing and disruptive behaviors. Of note, if compulsions and anxiety may represent dysfunctional coping strategies aimed at gaining control over a situation of unexpected threat (19), anger, and irritability have also been associated in children and youths with biased attention toward threatening information (20-22). Against this background, our findings support that the stressful conditions established by the lockdown, such as habit and social contact disruptions, may have acted as threat cues for patients, exacerbating dysfunctional behavioral and emotional responses.

Adding to this, we found an inverse relation between time dedicated to school activities during lockdown and the overall clinical symptomatology (i.e., shorter time dedicated to schoolwork was significantly related to greater worsening of symptoms, most notably rage attacks and OCS). Intuitively, subjects facing greater symptom exacerbation during the lockdown may have been more prone to concentration issues. Also, a reduced time for sport and physical activity, given their positive impact on well-being (23) and learning achievements in children (24), may have influenced the amount of time dedicated to remote learning and the general mental health of our sample. Taken together, the worsened clinical condition and the reduced possibility of physical exercise may have impacted on the time spent in schoolwork by patients in our cohort, with a shift toward activities such as video games and social networking, as already reported in a population-based study on Middle Eastern Respiratory Syndrome (MERS) (25).

Finally, the present study outlines no negative effect of prolonged stay at home on parent-child relationships, which are referred as stable or even improved in the large majority of cases. In this regard, the only variable correlating to worsening was the presence of extended family help before the pandemic (i.e., grandparents/relatives looking after the child), which was presumably disrupted due to lockdown requirements.

Our study has several limitations, although some are common to the survey methodology. The choice of a digital survey was motivated by the need to rapidly reach out to a greater group of individuals living in areas of the country that were differently affected by the pandemic. As for surveys in general, our study has been prone to response biases which affect accuracy and consistency of the results. Nevertheless, to partly control for random answers and increase responders' reliability, we launched the survey through an advocacy group website, thus attempting to gather data from individuals who were familial with and interested in the topic of tic disorders. Given such demographic aspects, referral biases were also possible (i.e., a higher participation in the survey by those living the more stressful situations). However, our data revealed a considerable number of cases reported as stable or even improved. This issue also suggests the possibility of a mitigation effect played by the lockdown on tics and related symptoms in a specific subgroup of individuals. Whether a determinant or a consequence of negative social interactions, many children with tics experience high social anxiety $(26,27)$. Thus, reduction of societal stress due to limited social exposure may have been at play in part of the variance observed.

Finally, the cross-sectional and anonymous nature of our data has hindered the possibility of a follow-up. Future studies on longitudinal cohorts would clearly add deeper insight on long-term mental health impact of the current pandemic in selected subpopulations.

Taking into account these limitations, our study highlights that, for a substantial percentage of patients with TS, the lockdown imposed by the COVID-19 pandemic has been an extremely difficult period characterized by the worsening of the overall clinical condition. Remarkably, though based only on qualitative data, the increase of behavioral and emotional symptoms in our sample seems to parallel the increase in tic severity, which might be interpreted as a sign of the interrelatedness of symptoms in the broader TS spectrum.

There is a compelling need to carefully observe how this epochal event may impact on mental health and natural course of TS in the long term. In view of possible future lockdowns and prolonged stay-at-home orders, health authorities and clinicians should be aware of the risks for mental health in vulnerable populations, in order to ensure appropriate healthcare without undermining public health needs. 


\section{DATA AVAILABILITY STATEMENT}

The raw data supporting the conclusions of this article will be made available by the authors, without undue reservation.

\section{ETHICS STATEMENT}

Ethical review and approval was not required for the study on human participants in accordance with the local legislation and institutional requirements. Written informed consent to participate in this study was provided by the participants' legal guardian/next of kin.

\section{REFERENCES}

1. Dong E, Du H, Gardner L. An interactive web-based dashboard to track COVID-19 in real time. Lancet Infect Dis. (2020) 20:533-4. doi: 10.1016/S1473-3099(20)30120-1

2. Remuzzi A, Remuzzi G. COVID-19 and Italy: what next? Lancet. (2020) 395:1225-8. doi: 10.1016/S0140-6736(20)30627-9

3. "COVID-19 ITALIA"-Italian Civil Protection Department. Monitoring the Situation. (2020). Available online at: http://opendatadpc.maps.arcgis. com/apps/opsdashboard/index.html\#/b0c68bce2cce478eaac82fe38d4138b1 (accessed 30 April, 2020).

4. Huremović D. Psychiatry of Pandemics: A Mental Health Response to Infection Outbreak. Cham: Springer International Publishing (2019). doi: 10.1007/978-3-030-15346-5

5. Kim HC, Yoo SY, Lee BH, Lee SH, Shin HS. Psychiatric findings in suspected and confirmed middle east respiratory syndrome patients quarantined in hospital: a retrospective chart analysis. Psychiatry Investig. (2018) 15:35560. doi: 10.30773/pi.2017.10.25.1

6. Maunder R, Hunter J, Vincent L, Bennett J, Peladeau N, Leszcz M, et al. The immediate psychological and occupational impact of the 2003 SARS outbreak in a teaching Hospital. CMAJ. (2003) 168:1245-51.

7. Cohen E, Austin J, Weinstein M, Matlow A, Redelmeier DA. Care of children isolated for infection control: a prospective observational cohort study. Pediatrics. (2008) 122:e411-5. doi: 10.1542/peds.2008-0181

8. Kennedy P, Hamilton LR. Psychological impact of the management of methicillin-resistant Staphylococcus aureus (MRSA) in patients with spinal cord injury. Spinal Cord. (1997) 35:617-9. doi: 10.1038/sj.sc. 3100469

9. Page LA, Seetharaman S, Suhail I, Wessely S, Pereira J, Rubin GJ. Using electronic patient records to assess the impact of swine flu (influenza H1N1) on mental health patients. J Ment Health. (2011) 20:609. doi: 10.3109/09638237.2010.542787

10. Diagnostic and Statistical Manual of Mental Disorders. 5th ed. Arlington, VA: American Psychiatric Association (2013).

11. Robertson MM, Eapen V, Singer HS, Martino D, Scharf JM, Peristera Paschou P, et al. Gilles de la tourette syndrome. Nat Rev Dis Primers. (2017) 3:16097. doi: 10.1038/nrdp.2016.97

12. Leckman JF. Tourette's syndrome. Lancet. (2002) 360:157786. doi: 10.1016/S0140-6736(02)11526-1

13. Conelea CA, Woods DW. The influence of contextual factors on tic expression in Tourette's syndrome: a review. J Psychosom Res. (2008) 65:48796. doi: 10.1016/j.jpsychores.2008.04.010

14. Goetz CG, Leurgans S, Chmura TA. Home alone: methods to maximize tic expression for objective videotape assessments in gilles de la Tourette syndrome. Mov Disord. (2001) 16:693-7. doi: 10.1002/mds.1159

15. Piacentini J, Himle MB, Chang S, Baruch DE, Buzzella BA, Pearlman A, et al. Reactivity of tic observation procedures to situation and setting. J Abnorm Child Psychol. (2006) 34:647-56. doi: 10.1007/s10802-006-9048-5

16. Buse J, Kirschbaum C, Leckman JF, Münchau A, Roessner V. The modulating role of stress in the onset and course of Tourette's syndrome:

\section{AUTHOR CONTRIBUTIONS}

GC and VB contributed to the conception, design of the study, and wrote the first draft of the manuscript. GC, VB, and FV organized the database. FCh performed the statistical analysis. FCa contributed to the conception, design of the study, and revised the manuscript. All authors contributed to manuscript revision, read, and approved the submitted version.

\section{ACKNOWLEDGMENTS}

We are grateful to the families who participated in the survey.

a review. Behav Modif. (2014) 38:184-216. doi: 10.1177/01454455145 22056

17. Steinberg T, Shmuel-Baruch S, Horesh N, Apter A. Life events and Tourette syndrome. Compr Psychiatry. (2013) 54:46773. doi: 10.1016/j.comppsych.2012.10.015

18. Abad C, Fearday A, Safdar N. Adverse effects of isolation in hospitalised patients: a systematic review. J Hosp Infect. (2010) 76:97-102. doi: 10.1016/j.jhin.2010.04.027

19. Marks IM, Nesse RM. Fear and fitness: an evolutionary analysis of anxiety disorders. Ethol Sociobiol. (1994) 15:24761. doi: 10.1016/0162-3095(94)90002-7

20. Salum GA, Mogg K, Bradley BP, Stringaris A, Gadelha A, Pan PM, et al. Association between irritability and bias in attention orienting to threat in children and adolescents. J Child Psychol Psychiatry. (2017) 58:595602. doi: 10.1111/jcpp.12659

21. Leibenluft E, Stoddard J. The developmental psychopathology of irritability. Dev Psychopathol. (2013) 25:1473-87. doi: 10.1017/S0954579413000722

22. Avenevoli S, Blader JC, Leibenluft E. Irritability in youth: an update. J Am Acad Child Adolest Psychiatry. (2015) 54:881-3. doi: 10.1016/j.jaac.2015. 08.012

23. Mandolesi L, Polverino A, Montuori S, Foti F, Ferraioli G, Sorrentino $\mathrm{P}$, et al. Effects of physical exercise on cognitive functioning and well-being: biological and psychological benefits. Front Psychol. (2018) 9:509. doi: 10.3389/fpsyg.2018.00509

24. Donnelly JE, Hillman CH, Castelli D, Etnier JL, Lee S, Tomporowski $\mathrm{P}$, et al. This summary was written for the American College of Sports Medicine by. Phys Act Fitness Cogn Funct Acad Achiev Child. (2016) 48:12234. doi: 10.1249/MSS.0000000000000966

25. Jeong H, Yim HW, Song YJ, Ki M, Jung-Ah M, Cho J, Chae JH. Mental health status of people isolated due to middle east respiratory syndrome. Epidemiol Health. (2016) 38:e2016048. doi: 10.4178/epih.e2016048

26. Conelea CA, Woods DA, Zinner SH, Budman C, Murphy T, Scahill LD, et al. Exploring the impact of chronic tic disorders on youth: results from the Tourette Syndrome Impact Survey. Child Psychiatry Hum Dev. (2011) 42:219-42. doi: 10.1007/s10578-010-0211-4

27. Bitsko RH, Holbrook JR, Visser SN, Mink JW, Zinner SH, Ghandour RM, et al. A national profile of Tourette Syndrome, 2011-2012. J Dev Behav Pediatr. (2014) 35:317-22. doi: 10.1097/DBP.0000000000000065

Conflict of Interest: The authors declare that the research was conducted in the absence of any commercial or financial relationships that could be construed as a potential conflict of interest.

Copyright (C) 2020 Conte, Baglioni, Valente, Chiarotti and Cardona. This is an openaccess article distributed under the terms of the Creative Commons Attribution License (CC BY). The use, distribution or reproduction in other forums is permitted, provided the original author(s) and the copyright owner(s) are credited and that the original publication in this journal is cited, in accordance with accepted academic practice. No use, distribution or reproduction is permitted which does not comply with these terms. 